\title{
Sex determination from femur using length of femur in Maharashtra
}

\author{
Rajeshwari S. Bhosale ${ }^{1}$, Dr. B. R. Zambare ${ }^{2}$ \\ ${ }^{1,2}$ (Department Of Anatomy, Padmashree Vithalrao Vikhe Patil Foundation's Medical College / Maharashtra \\ University Of Health Sciences, India)
}

\begin{abstract}
Identification of sex from skeleton is an important demographic assessment in medico legal investigations. Length of femur is an important and reliable skeletal element for sex determination. The present study aims at obtaining results from the length of femur in Maharashtra and to develop Standards in determination of sex; the study was carried out using 184 dry normal adult human femora (136 male 48 female) Collected from dept. of Anatomy Padmashree V.K. Patil Medical College Ahmednagar. The Osteometric board was utilized to find the length of femur which is considered as the maximum Vertical distance between the upper end of the head of femur and the lowest point on femoral Condyle. The mean Values obtained were $450.82 \mathrm{~mm}$ and $416.49 \mathrm{~mm}$ for Right sided male and female; and $452.37 \mathrm{~mm}$ and $420.43 \mathrm{~mm}$ for Left sided male and female respectively. Statistical Analysis revealed higher Value in male which was highly Significant $(P<0.001)$ on both sides. Statistical analysis showed that the demarking point so far as the right femora is concerned with a maximum length more than $>476.80 \mathrm{~mm}$ were definitely male and that less than $<379.91 \mathrm{~mm}$ were definitely

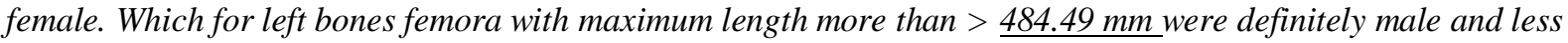
than $<\underline{385.83 \mathrm{~mm}}$ were definitely female. Maximum length Identified $13.33 \%$ of right male femora, $4.37 \%$ of right female femora, $\underline{7.24 \%}$ of left male femora and $\underline{8 \%}$ of left female femora.
\end{abstract}

Keywords-Condyle, Femora, Osteometric Board, Sex Determination, Skeleton.

\section{INTRODUCTION}

The assessment of human sex from skeletal parts is of particular Importance in forensic Osteology and it relies heavily on the up-to-date techniques in order to provide accurate information to medico legal system. With time the assessment had a shift from Visual analysis to anthropometric measurements which when processed through modern Statistical techniques has made sex determination more objective.

Sex determination is relatively easy if the entire skeleton is available, pelvis and skull are more reliable bones for this purpose ${ }^{[1]}$. However in medico legal Cases one does not always have a complete pelvis or skull, hence it is important to be able to assess sex from the other parts of the skeleton also.

Among long bones the femur received a special attention by the researchers for the Usage of femur in sex determination fragments of skeletal remains of femur were used to determine Sex ${ }^{[2]}$ with max. length.

Sexual dimorphism of maximum length of femur has been Studied by Several workers in different populations Di Bennardo R \& Taylor J.V. (1979) ${ }^{[2]}$ \& C. Singh and Singh (1972) in Varanasi Zone (India) ${ }^{[3]}$, Dittrick J. and Suchey J.M. (1986) in Prehistoric Central California Skeletal remains ${ }^{[4]}$, Iscan M.Y. and Shihai D. in Chinese femora ${ }^{[5]}$, Steyn M. and Ischaw M.Y.(1997) in South African whites ${ }^{[6]}$ King CA, Ischcan M.Y. and Loth S.R.(1998) in Thai femur ${ }^{[7]}$, Leelavati R. and etal (2000) in femora from Karnataka ${ }^{[8]}$, Ruma Purkait and Hiresh Chandra (2002) in Indians ${ }^{[9]}$, Depending on the population Samples involved Standards of morphological and morphometric attributes in skeleton may differ (Krogman and Iscan) ${ }^{[1]}$ so the present study was carried out to ascertain sexual dimorphism of maximum femoral length in femora from Maharashtra region.

\section{MATERIAL AND METHOD}

The present study was Carried out Using 184 human adult femora out of which 136 male (67 of right and 69 left side) and 48 female( 23 right side and 25 left side) Collected from the dept. of anatomy of Padmashree Dr. V.K. Patil Medical College Ahmednagar. Samples with any pathological changes or fracture were excluded.

An Osteometric board was utilized to measure maximum length of femur which is taken as the maximum Vertical distance between the upper end of head of femur and lowest point on femoral Condyle.

Photograph (3) - Osteometric board, Vernier Caliper and femur measured on the Osteometric board. 
III. RESULTS

Statistical Values For maximum Femoral Length

\begin{tabular}{|c|c|c|c|c|}
\hline Statistical Values & \multicolumn{2}{|c|}{ Right } & \multicolumn{2}{c|}{ Left } \\
\hline & $\mathrm{M}(\mathrm{n}=)$ & $\mathrm{F}(\mathrm{n}=)$ & $\mathrm{M}(\mathrm{n}=)$ & $\mathrm{F}(\mathrm{n}=)$ \\
\hline Range$(\mathrm{mm})$ & $394-507$ & $375-474$ & $394-508$ & $380-480$ \\
\hline Mean & 450.82 & 416.49 & 452.37 & 420.43 \\
\hline S.D. & 23.84 & 19.83 & 22.63 & 21.38 \\
\hline T-Value & 6.90 & - & 6.70 & - \\
\hline P-Value & $\mathrm{P}<0.001$ & - & $\mathrm{P}<0.001$ & - \\
\hline Calculated Range \pm 3SD & $379.88-523.33$ & $358.16-476.80$ & $385.83-521.37$ & $356.49-484.39$ \\
\hline D.P. & $>476.80$ & $<379.91$ & $>484.48$ & $<385.83$ \\
\hline \% Identified By D.P. & $13.33 \%(\mathrm{n}=9)$ & $4.37 \%(\mathrm{n}=1)$ & $7.24 \%(\mathrm{n}=5)$ & $8 \%(\mathrm{n}=2)$ \\
\hline
\end{tabular}

The above table shows a definite sexual classification in male left bone $(>484.48)$ is $7.24 \%(n=5)$ and female left bone $(<385.83)$ is $8 \%(n=2)$.

Differences in Value in the right and left male and right and left female were not statistically significant and were not evaluated further.

Considering the statistical analysis 1) the right male femur in which the maximum length Varied from $394-507 \mathrm{~mm}$ with mean of $450.82 \mathrm{~mm}, \mathrm{SD}=23.84(\mathrm{P}<0.001)$ and that in right female Varied from $375-474$ $\mathrm{mm}$ with a mean $416.49 \mathrm{~mm}$ and $\mathrm{SD}=19.83$. It is also observed that the mean Value of the maximum length was higher in male as Compared to that of female and was highly Statistically Significant with P $<0.001$ on both sides. Using the demarking point analysis a definite sexual classification in right male bone $(>476.80 \mathrm{~mm}) \mathrm{was}$ $13.33 \%(\mathrm{n}=9)$ and in right female bone $(<379.91 \mathrm{~mm})$ was $4.37(\mathrm{n}=1)$. Considering the left male femur the maximum length Varied from 394-508 mm with a mean of 452.37 and SD=22.63. Similarly for left female femur Varied from 380-470 mm having mean of $420.43 \mathrm{~mm}(\mathrm{SD}=21.38)$.

Mean Value of maximum length was higher in male compared to that of female. The t-Value and pValue showed the difference in mean maximum length in male and female was highly Statistically Significant with $\mathrm{p}<0.001$.

\section{DISCUSSION}

Mean Value of maximum length in males was higher than that of females, it is also noted that from the $t$-Value and $p$-Values the difference in mean maximum length in males and females was highly Statistically Significant with $\mathrm{p}<0.001$ on both sides (right and left).

The Calculated Range (mean \pm 3 SD) for right male was $379.88-523.33 \mathrm{~mm}$ and that for right female it was 358.16-476.80 $\mathrm{mm}$ depending on this the Demarking points can be calculated that is the measurement above which no female bone can be found and below which no female femora can be found; hence from this the right femur with maximum length more than $>476.80 \mathrm{~mm}$ can be correctly classified as male and right femora with maximum length less than $<379.88 \mathrm{~mm}$ can be classified as female, however if the length is between $379.88 \mathrm{~mm}$ and $476.80 \mathrm{~mm}$ it is not possible to determine the sex due to overlapping . Using the demarking point analysis a definite Sexual Classification can be made where the right male femora bone $(<476.80 \mathrm{~mm})$ was $13.33 \%$ and the right female femora bone $(<379.88 \mathrm{~mm})$ was $4.37 \%$.

Considering the left male femora the calculated range is $385.83-476.80 \mathrm{~mm}$ and for left female femora it is between $356.49-484.39 \mathrm{~mm}$. Using Demarking point analysis the left femur with length more than > 484.48 $\mathrm{mm}$ can be correctly classified as male and right femur with length less than $<385.83 \mathrm{~mm}$ can be correctly classified as female; however Sexing of femora is not possible if the length is between $484.48 \mathrm{~mm}$ and 385.83 $\mathrm{mm}$ due to Overlapping. Hence the \% of bone Identified using these D.P.'s is $7.24(\mathrm{n}=1)$ in male left bone and in left female bone is $8 \%(n=2)$. Generally it is seen that the male bones are longer and massive and this accounts for the greater Value of mean of maximum femoral length in male on both sides.

TABLE: A Comparison of Maximum femoral length in MALES

\begin{tabular}{|c|c|c|c|}
\hline Population and Study & \multicolumn{3}{|c|}{ MALES } \\
\hline & Mean & SD & Identi \\
\hline Di Bernardo and Taylor Am. black & 475 & 31.4 & - \\
\hline Dittrick J and Suchey M , California & 420.6 & 17.2 & $79.55 \%$ \\
\hline J. Schan and Shihai Chinese & 400.97 & 19.71 & - \\
\hline J. Schan and Steyn , South African Whites & 469.68 & 27.97 & - \\
\hline King CA etal Thai & 429.4 & 21.38 & - \\
\hline Purkait and Chandra India & 451.47 & 23.38 & $84.50 \%$ \\
\hline Present Study & Right=450.82 & 23.84 & $13.33 \%$ \\
\hline
\end{tabular}


Sex determination from femur using length of femur in Maharashtra

TABLE: B Comparison of Maximum femoral length in FEMALES

\begin{tabular}{|c|c|c|c|}
\hline Population and Study & \multicolumn{3}{|c|}{ FEMALES } \\
\hline & Mean & SD & Identi \\
\hline Di Bernardo and Taylor Am. black & 443 & 23.6 & $71.00 \%$ \\
\hline Dittrick J and Suchey M , California & 420.6 & 17.2 & $79.55 \%$ \\
\hline J. Schan and Shihai Chinese & 400.97 & 19.71 & - \\
\hline J. Schan and Steyn , South African Whites & 469.65 & 20.65 & - \\
\hline King CA etal Thai & 397 & 19.6 & - \\
\hline Purkait and Chandra , Indian & 403.69 & 17.79 & $91.30 \%$ \\
\hline Present Study & 417.48 & 19.74 & $4.35 \%$ \\
\hline & Right=416.49 & 19.83 & $4.37 \%$ \\
\hline
\end{tabular}

From above table it is observed that there is difference in the mean Value of femoral length in between populations the reason may be genetic, constitution, diet or Nutrition, physical activity. Comparison of maximum femoral length of male between present study and other studies as shown in table 'A'. The mean for maximum femoral length in present study was $450.82 \mathrm{~mm}$ (right) and $452.37 \mathrm{~mm}$ (Left) and other studies Varies from $429.4 \mathrm{~mm}$ to $469.68 \mathrm{~mm}$. The mean maximum length in present study was higher than Thai ${ }^{[7]}$ and Chinese ${ }^{[5]}$ femora ${ }^{\text {Ref }}$ and lower than American black ${ }^{[3]}$ and South African White ${ }^{[6]}$ which is comparable with values seen in American whites ${ }^{[3]}$, Californian Samples. ${ }^{[4]}$

Similarly from table 'B' which shows a comparison of femoral length in females with other studies, In the present study the mean of maximum femoral length Varies between $416.49 \mathrm{~mm}$ (right) and $420.43 \mathrm{~mm}$ (left) where as in other studies Varied from $397 \mathrm{~mm}$ to $443 \mathrm{~mm}$; the mean maximum femoral length in females in present study was lower than the American Blacks ${ }^{[3]}$ and South African Whites ${ }^{[6]}$ and was comparatively higher than the Thai's ${ }^{[7]}$; and samples from Bhopal ${ }^{[10]}$ and was similar to the Values of the Californian's. ${ }^{[4]}$

On Comparison of table 'A' and 'B' marked differences can be observed where a low $\%$ of correct sexual classification can observed in present study, while most of the above studies were based on multivariate analysis and demarking point analysis was utilized in present study.

The range that is the maximum and maximum Values for any parameter can be calculated by using the formula (mean $\pm 3 \mathrm{SD}$ ) this covers a wide $\%$ of population of that area, as the $\%$ of correctly sexed bones dropped down by using the demarking point analysis but $100 \%$ classification accuracy is achieved for any sample for the region which is useful in medico legal cases ${ }^{[11]}$ compared to multivariate analysis the D.P. analysis is an easier method.

\section{CONCLUSION}

Although all the measurements were more in Males as compared to that of the females in conclusion of the present study fulfils the need to update Osteometric Standards that can be used in determining sex in the identification process, the values of the mean maximum length in male femora in Maharashtra was $\underline{450.82 \mathrm{~mm}}$ (right) and $452.37 \mathrm{~mm}$ (left) and that in female $416.49 \mathrm{~mm}$ (right) and $420.43 \mathrm{~mm}$ (left) \% identified $\underline{13.33 \% \text { of }}$ right male femora, $\underline{7.24} \%$ of left male femora, $\underline{4.37 \%}$ of right female femora and $\underline{8 \%}$ of left left female femora.

\section{Journal Papers:}

\section{REFERENCES}

[1] DiBennardo R. and Taylor J. V., Classification and misclassification in sexing the black femur by discriminant function analysis, American Journal of Physical Anthropology1982, 58, 145-151.

[2] Singh S. P. and Singh S., The sexing of adult femora: Demarking points for Varanasi zone, Journal of the Indian Academy of Forensic Sciences 1972 B, 11:1-6.

[3] Dittrick J. and Suchey J. M., Sex determination of prehistoric central California skeleton remains using discriminant analysis of the femur and humerus, American Journal of Physical Anthropology 1986, 70: 3-9.

[4] Iscan M.Y. and Shihai D., Sexual Dimorphism in the Chinese Femur. Forensic Science International June 1995, 74(1-2), 79-87.

[5] Steyn M. and Iscan M. Y., Sex determination from the femur and tibia in South African whites, Forensic Science International 1997, 90: 111-119.

[6] King C.A., Iscan M. Y. and Loth S.R., Metric and comparative analysis of sexual dimorphism in the Thai Femur. Journal of Forensic Science 1998, 43(5): 954-958

[7] Leelavathy N, Rajangam S, Janakiram S., Thomas IM, Sexing Of The Femora. Indian Journal of Anatomical. Society of India, 2000, 49(1) 17-20.

[8] Purkait R. and Chandra H., Sexual Dimorphism in Femora: An Indian Study. Forensic Science Communications 2002 July, 4(3): 1-6.

[9] Pal G.P., Reliability of criteria used for sexing of hip bone. Journal of Anatomical Society of India. 2004, 53

\section{Books:}

[10] Krogman, W. M. and Iscan, M. Y. Human skeleton in forensic medicine $2^{\text {nd }}$ Edition (Charles C. Thomas, Springfield, 1986).

[11] Singh I. P. \& Bhasin M. K.,Manual of biological anthropology in Osteometry $1^{\text {st }}$ Edition Kamla-Raj Prakashan, Delhi, 2004, pp:7983 